Kostas Gemenis*

\title{
The Impact of Voting Advice Applications on Electoral Turnout: Evidence from Greece
}

\author{
https://doi.org/10.1515/spp-2018-0011
}

\begin{abstract}
A new aspect of electoral campaigns in Europe, and increasingly elsewhere as well, has been the proliferation of the online voter information tools, widely known in the political science community as Voting Advice Applications (VAAs). By accessing VAAs, users are provided with information about the degree of congruence between their policy preferences and those of different parties or candidates. Although the exact mechanisms have not been rigorously investigated, a series of studies across European countries, such as Finland, Germany, Italy, the Netherlands, and Switzerland have demonstrated a link between the use of VAAs and electoral turnout. The aim of this paper is to contribute to this growing literature by analyzing previously untapped data from Greece, extending the empirical literature to a country where VAA effects have not been investigated before. The analysis indicates that the effect of VAAs in Greece is marginal to nonexistent while there seems to be no evidence of the hypothesized information mechanism which purportedly drives such effects. The paper concludes with suggestions that future studies of VAA effects on turnout can address in their design.
\end{abstract}

\footnotetext{
MPIfG Journal Article

Kostas Gemenis: The Impact of Voting Advice Applications on Electoral Turnout: Evidence from Greece. In: Statistics, Politics and Policy 9(2), 161-179 (2018). De Gruyter

The original publication is available at the publisher's web site: https://doi.org/10.1515/spp-2018-0011

1 Introduction

The MPIfG Journal Articles series features articles by MPIfG researchers and visiting scholars published in peer-reviewed journals. Max Planck Institute for the Study of Societies (MPIfG) Cologne | www.mpifg.de
}

The declining electoral turnout rates across established democracies have generally been seen as a sign of citizen disengagement and apathy, that poses a danger to democratic legitimacy and representation (Lijphart 1997). Some of the proposed remedies focus on electoral engineering, such as increasing the proportionality of electoral systems, reducing voting complexity, or introducing compulsory voting, without necessarily addressing the underlying causes of the decline in turnout (Franklin 1999). Other approaches, especially in the US, focus on the impact of social norms through communication efforts such as "get-outthe-vote" strategies (Green and Gerber 2015).

*Corresponding author: Kostas Gemenis, Max Planck Institute for the Study of Societies, Cologne, Germany, e-mail: gemenis@mpifg.de 
The advent of the internet has brought with it additional strategies to address the declining turnout rates, focusing on reducing the costs usually associated with the act of voting. For instance, remote electronic voting addresses electoral costs (Germann and Serdült 2017), while the dissemination of political information online addresses the cost of gathering such information (Tolbert and McNeal 2003; Xenos and Moy 2007). Within the latter approach, a particular type of online tools known as "Voting Advice Applications" (VAAs) promise to address information asymmetries directly by allowing citizens to compare their preferences on a wide range of policy issues to those of political parties and candidates contesting elections.

VAAs were originally developed as civic education tools. Starting with Stemwijzer in the Netherlands in 1989, and continuing with other highly popular VAAs such as Vaalikone in Finland, Wahl-O-Mat in Germany, and Smartvote in Switzerland, public agencies have promoted VAAs with the intention of enhancing political knowledge. From the perspective of VAA designers, the presumption is that, by communicating information about the policy positions of parties and/ or candidates and by showing how well these match users' preferences, VAAs can work as voter information tools and help citizens to make informed decisions when casting their vote. Although their efficacy in terms of boosting political participation is still a matter of debate, VAAs have become one of the top choices among young people when asked about different proposals for tackling low electoral participation (Cammaerts et al. 2016).

Nevertheless, and despite the widespread use of VAAs, we still have a rather limited understanding of their role in terms of citizens' voting behavior. While several studies have established the link between VAA usage and voter turnout, researchers have only just begun to acknowledge, let alone address, issues surrounding causal inference and measurement error which can compromise the quality of inferences. Moreover, research has not explored empirically the hypothesized mechanisms between VAA usage and turnout in order to establish links between VAA design and the purported effects, which is necessary if we want to evaluate the efficacy of VAAs as civic education tools.

The paper begins by outlining the theory linking VAAs and electoral turnout in the context of the seminal contribution by Downs (1957), and summarizes the findings of the relevant empirical literature. The empirical part of this paper offers some evidence from Greece, paying particular attention to the context in which VAAs operate. The findings are critically discussed within the existing empirical literature, and the paper offers some concluding remarks on how researchers can design studies that adequately address and study the impact of VAAs on political participation, and evaluate the efficacy of VAAs as voter information tools. 


\section{Theory and Literature Review}

According to Downs (1957), participation in democratic elections is dependent on cost/benefit calculations made by citizens. While cost refers to the time spent during the act of voting, depending on specific barriers set by electoral laws (such as the need to register), the benefit is primarily a function of how different from one another citizens deem the political parties to be. Furthermore, the effect of this benefit on participation is conditional on how pivotal the election is, which would imply that differences in platforms might be translated to changes in policy by the winning party (Downs 1957: pp. 270-272). In order to be able to detect differences in policy among parties, citizens must collect and process information, which also comes at a cost. For most citizens, therefore, the costs outweigh the benefits of voting, which makes the observed participation rates paradoxical. Nevertheless, provided that citizens value living in a democracy, they should recognize that the "cost of voting is lower than the cost of becoming informed" and that "the potential ill effects of not voting are worse than those of not becoming informed" (Downs 1957: p. 269) and therefore find it preferable to cast an uninformed vote than no vote at all.

Notwithstanding the literature that proposes increasing voter turnout through electoral engineering (Lijphart 1997; Franklin 1999), or through "get-outthe-vote" communication strategies (Green and Gerber 2015), there is a considerable strand in the literature which has investigated the relationship between political information and turnout (Lassen 2005; Degan 2006; Larcinese 2009). Within this context, the advent of the internet has offered technological solutions that directly address the information cost of voting. Early studies have hypothesized and demonstrated that internet usage increases political knowledge and turnout (Tolbert and McNeal 2003; Xenos and Moy 2007; Hirzalla et al. 2010), although such effect might have been compounded by selection bias as internet usage correlates with political interest (Bimber 2001).

While the internet simply allows citizens, especially those who traditionally have fewer resources at their disposal, to access political information at a low cost, VAAs go further and address information gaps and asymmetries directly. They do this by offering personalized information, precisely where citizens are expected to benefit from voting on how the policy positions of different parties relate to one another and to the preferences of the citizens themselves. VAAs therefore address what Downs (1957: p. 210) identified as "transferable costs" that can be delegated to experts, leaving citizens to bear only the cost of assimilating the information and making decisions on whether to vote or not, in addition to the (rather minimal) costs associated with the actual act of the voting. Moreover, the information provided by VAAs is not only tailored to each citizen and free of 
charge, it is also relatively unbiased. While Downs (1957: pp. 213-214) anticipated that information flows from traditional media will be tainted by partisan bias potentially leading to "echo chambers," whatever flaws present in the information provided by VAAs are associated with limitations in their design rather than with partisan considerations (see Walgrave et al. 2009; Mendez 2012; Gemenis 2013; Germann et al. 2014; Rosema and Louwerse 2016).

Considering that VAAs address the core of the calculus of voting in a hitherto unparalleled way, one would naturally expect that VAA usage could increase turnout. Consequently, we have observed the publication of a wealth of studies on the subject, considering the degree of specialization in this nascent field of enquiry. Fortunately, investigation of the link between VAA usage and turnout has avoided sterile discussions over aggregate data and addressed the link directly at the level of individual citizens. The question of whether usage of VAAs makes citizens more likely to vote has thus been examined across several countries, using different data sources and research designs.

In one of the earliest studies on VAA usage and its effects Marschall and Schmidt (2008) analyzed 13,557 online respondents who were recruited after completing the 2005 German federal election Wahl-O-Mat, a highly popular VAA in Germany that is designed by the German Federal Agency for Civic Education (BPB). Respondents were asked to assess whether using the Wahl-O-Mat motivated them to vote; Marschall and Schmidt (2008: p. 270) found that 7.8\% of these users declared that they were motivated by the VAA to vote. Given that self-assessments of VAA effects among VAA users are wildly inaccurate (see Walgrave et al. 2008), in a subsequent study Marschall and Schultze (2012) used data from the 2009 German Longitudinal Election Study (GLES), an online panel survey where respondents were recruited using quotas for gender, education, and age. The preelection wave of GLES included 1153 completed questionnaires and questions on whether respondents had used Wahl-O-Mat. After controlling for several demographic variables in logistic regression, Marschall and Schultze (2012) found that Wahl-O-Mat users were 1.8 times more likely to report that they would vote in the 2009 federal election compared to non-users.

A similar study was conducted in the Netherlands in the context of the 2010 parliamentary election. Although Kruikemeier et al. (2014) addressed the issue of political uses of the internet more generally, their data included a question on whether respondents had used StemWijzer, a highly popular VAA in the Netherlands designed by ProDemos, a civic education agency that is partly subsidized by the government. Kruikemeier et al. (2014) analyzed 985 respondents drawn from both waves of a nationally representative pre-election online panel and, after controlling for several demographic variables in logistic regression, concluded that the use of StemWijzer led to a statistically significant increase in the 
willingness to vote if an election would be held that day. While it is difficult to gauge impact estimates from the regression models reported in Kruikemeier et al. (2014) due to the inclusion of interaction effects, Gemenis and Rosema (2014) attempted to do so by using the post-election survey of the 2006 Dutch Parliamentary Election Study (DPES), which included questions on VAA usage. Using data from the 2806 respondents of the face-to-face survey, Gemenis and Rosema (2014) used entropy balancing to match VAA users to non-users on age, gender, education, political interest, knowledge, and party identification and estimated that the odds of voting among VAA users were 4.2 times higher than those among individuals who did not use a VAA. Moreover, by simulating the absence of VAA in their model, they concluded that VAAs contributed about 4.3\% in the aggregate turnout (Gemenis and Rosema 2014: p. 286).

In Switzerland, Fivaz and Nadig (2010) examined 27,320 respondents of a three-wave online survey who were recruited after completing the Smartvote VAA for the 2007 parliamentary elections in Switzerland. Respondents in this survey were asked to assess whether using Smartvote motivated them to vote. Based on these self-assessments, Fivaz and Nadig (2010: p. 184) found that almost 40\% of the respondents declared at least some influence, and concluded that if they projected from this sample to the population of roughly 375,000 Smartvote users, roughly "6 percent of Swiss voters were positively influenced in their decision to cast their vote in the 2007 elections." Using the same data, Ladner and Pianzola (2010) perfomed a similar analysis and concluded that Smartvote was responsible for $0.6-1.1 \%$ of turnout in the 2007 election. Germann and Gemenis (2018) attempted to approximate the true effect of Smartvote on turnout in the 2007 election using the 4392 respondents of the Swiss election study (Selects), a nationally representative (with oversampling among smaller cantons) telephone survey. The Selects survey included a question on whether the respondent had used Smartvote. To account for self-selection in terms of VAA usage, Germann and Gemenis (2018) used entropy balancing to match users to non-users on a wide range of demographic variables as well as past turnout, and found that using Smartvote increased citizens' probability of voting by between 3 and $11.8 \%$, with the effect being stronger among younger users. The effect translated to about $0.2-2 \%$ in the aggregate turnout, at a very competitive cost of about 8.8 CHF per mobilized citizen, which made Smartvote a particularly cost-effective way to mobilize voters compared to traditional get-out-the-vote methods. In addition, Germann and Gemenis (2018) performed a series of robustness checks and replicated these effects using the 2011 and 2015 Selects studies.

In a comparative study involving election study data from Finland (2007, 2011), Germany (2009), the Netherlands (2003, 2006, 2010), and Switzerland (2007, 2011), Garzia et al. (2014) conducted logistic regression analyses controlling 
for a wide range of demographic and attitudinal variables and found statistically significant effects of VAA usage on turnout, with increases in individual probabilities to vote ranging from a little more than 1.5\% (Netherlands 2003) to over 10\% (Switzerland 2007), while aggregate effects ranged from about 0.25\% (Germany 2009), to almost 2.5\% (Finland 2007). However, when the same data were analyzed using selection models instrumenting for gender and ideology (Garzia et al. 2014: pp. 110-112), in half of the studies the effects were conspicuously absent. Moreover, a re-analysis of the same data with a few additional surveys (Finland 2003, Germany 2013, the Netherlands 2012, and the European Election Study 2009) by Garzia et al. (2017), using coarsened exact matching to account for selfselection, found yet more differences in terms of the magnitude of effects. In addition, considering that the individual and aggregate effects found by Garzia et al. (2014) were often different than those found by other studies using the same data, we understand that most of the estimated effects rest heavily on the assumptions made by the different statistical methods that were used. Furthermore, in a study analyzing a sample of 647 respondents drawn from over the 40,000 users of 2012 iVote VAA in Taiwan, Wang (2016) found no effect on the change in the intention to vote between the pre and post-election surveys.

In addition to the analysis of observational data, the fact that some countries have relatively low rates of VAA usage has allowed researchers to conduct experiments where randomization of respondents to treatment and control conditions increases our confidence in the reported estimates in terms of internal validity. Vassil (2011) conducted a survey experiment in Estonia using respondents recruited through university online mailing lists. Respondents were randomly assigned either using the Estonian version of the EU Profiler VAA or to a control group, and 394 respondents completed both waves of the online survey. Using the difference in the intention to participate in the 2009 election to the European Parliament between the two waves of the survey as the dependent variable, and accounting for divergence from the experimental assignment using an instrumental variable approach, Vassil (2011: pp. 145-146) found very modest effects of VAA usage. Using a similar design, Enyedi (2016) analyzed 2502 respondents of a two-wave online panel before and after the 2010 parliamentary election in Hungary. Respondents were assigned using either of two VAAs (Választási Iránytü and Szavazatszonda), both of the VAAs, or to a control group, and the dependent variable was operationalized as the difference between the pre-election intentions and the post-election self-reported turnout. Enyedi (2016) looked not only at VAA usage but also at whether the results obtained by the VAAs confirmed or disconfirmed their voting intentions, and whether the two VAAs provided converging or diverging results according to respondents' recollections. He concluded that after controlling for pre-electoral intentions to vote, none of the turnout-related tests was statistically 
significant (Enyedi 2016: p. 1011), although the results were not actually presented in the paper, which would have allowed us to gauge the size of the estimated effects.

Garzia et al. (2017) also reported results from a similar experiment in Italy, among 908 respondents of the online panel of the Italian election study (ITANES). Respondents were randomly assigned to a "mock VAA" that was created for the purposes of the experiment and to a control group, and the dependent variable was operationalized as the difference between the pre-election intentions and the post-election self-reported turnout. Garzia et al. (2017: p. 438) concluded that the proportion of mobilized citizens among those who used the VAA was 10.7 percentage points higher than in the control group. Diverging from aforementioned experimental design, Mahéo (2017) conducted a field experiment of VAA effects in Quebec by recruiting 389 participants in various public locations. Participants were offered $\$ 15$ and were randomly assigned to using a VAA or taking a movies quiz, with the dependent variables being the intention to vote in the 2014 election measured right after the intervention, the reported turnout measured through a follow-up telephone survey one week after the election, and the validated turnout provided by the Quebec electoral body. Mahéo (2017: p. 522) found statistically significant effects among participants with lower levels of education when voting intentions were examined, but not for validated turnout. Even in this case, however, the effect size was consistent with other studies, although the study was probably underpowered (277 respondents in the model for validated turnout after listwise deletion) to detect statistically significant effects of that size.

\section{Data and Method}

VAAs first became available in Greece with the local version of the 2009 EU Profiler. Even though this VAA attracted a very modest number of users, within less than 18 months a team of researchers from Aristotle University in Thessaloniki and the University of Zurich created the first Greek VAA, HelpMeVote, which was made available for the 2010 regional elections. By the May 2012 parliamentary election, the two institutions had established two different VAAs that have been running in parallel since then: HelpMeVote and Choose4Greece, respectively (Gemenis et al. 2015). Usage of these VAAs remains moderate compared to other countries (Marschall 2014), with roughly 480,000 (May 2012)-570,000 (January 2015) users for HelpMeVote, and 58,000 (January 2015)-98,000 (September 2015) users for Choose4Greece.

In many respects, the emergence of VAAs in Greece has followed a more general trend of proliferation and professionalization of VAAs elsewhere in 
Europe (Garzia and Marschall 2014) and in other countries (Liao et al. 2016). There are, however, particular aspects in the Greek political context that make the study of VAA effects in Greece quite different compared to other countries. For one thing, voting in Greece is characterized by compulsory (if unenforced) voting, and relatively high (but continuously declining) turnout rates. ${ }^{1}$ Moreover, elections since 2012 have been characterized by record high levels of electoral volatility and a doubling in the effective number of parties with re-alignment of voters into a changing party system (Gemenis and Nezi 2015; Tsatsanis 2019).

This study uses three different data sources to investigate the possible VAA effects on turnout: two general surveys using representative samples of the voting population (Andreadis et al. 2016; Marantzidis et al. 2017) which are used to estimate the effect at the individual level, and data from the January 2015 Choose $4 G$ reece VAA (Konstantinidis et al. 2018) which are used to assess the purported information mechanism as outlined in the previous section.

Although Greece does not have an institutional structure to conduct election studies, there are two surveys that have included items related to VAAs. The 2012 post-election Voter Survey (Andreadis et al. 2016), a mixed-mode survey (online and face-to-face) which is part of Module 4 of the Comparative Study of Electoral Systems (CSES), included several items about HelpMeVote usage, while the two-wave telephone panel survey conducted for the "Collective Action of Indignant Citizens in Greece” (CAICG) project (Marantzidis et al. 2017) included a few items about VAA usage more generally. While the sampling of respondents and wording of items in these studies differs considerably, a consistent data analysis should produce estimates that are roughly comparable to each other and to similar studies in other countries.

In addition to survey data, the analysis of VAA log files allows additional insights to be drawn, especially with respect to the hypothesized information mechanism. Luckily, and contrary to other countries, VAA user data in Greece from both HelpMeVote and Choose4Greece has been made available to researchers. In particular, Choose 4Greece data have been used by numerous researchers in individual-level analyses (Nezi and Katsanidou 2014; Germann and Mendez 2016; Katsanidou and Otjes 2016; Mendez 2017). Like other VAAs designed by the PreferenceMatcher consortium, ${ }^{2}$ the January 2015 Choose4Greece included three pages of supplementary

\footnotetext{
1 Readers might argue that turnout rates in Greece do not appear particularly high. Official turnout rates, however, are underestimated due to failures in the updating the electoral registers (Gemenis 2008: pp. 97-98). Actual turnout figures in Greece are higher as much as 10 percentage points, compared to official figures, and researchers often adjust the turnout rates for Greece in order to account for this discrepancy (e.g. Franklin et al. 1996: p. 320).
}

2 See: http://www.preferencematcher.org. 
questions that were presented to users in addition to the pages asking users to state their policy preferences and the pages asking users to place themselves and political parties on general ideological scales (Konstantinidis et al. 2018). In particular, one of the supplementary questions asked users to indicate the likelihood that they would turn out to vote. As this question was given in two pages in Choose4Greece, one prior to the VAA results and the other right after, the design of Choose4Greece allows for a quasi-experimental investigation of VAA effects.

With respect to research design, an important question is whether the estimated effects are valid or whether they can be considered to be endogenous. Given that there are common determinants between VAA usage (Fivaz and Nadig 2010; Marschall and Schultze 2012; Garzia et al.2014) and individual-level turnout (Smets and van Ham 2013), many studies on VAA effects, and more generally on turnout, have turned to survey (Enyedi 2016; Garzia et al. 2017), field (Green and Gerber 2015; Mahéo 2017), and natural experiments (Lassen 2005) in order to gain leverage of internal validity. While well-designed randomized experiments are considered the gold standard in terms of internal validity, matching approaches have been proposed as second-best alternatives in estimating VAA effects (Gemenis and Rosema 2014; Garzia et al. 2017; Germann and Gemenis 2018).

Matching has several advantages over regression adjustment in the analysis of observational data (Austin 2011: pp. 417-418). Unlike regression, matching allows us to conceptualize VAA usage as a "treatment" that a group of citizens chooses to take (treatment group), while another group of citizens chooses not (control group). Matching directly models self-selection into this treatment variable by attempting to make comparable the distributions of the confounding variables between the treatment and control groups. Moreover, matching allows researchers to use exact measures to assess the balance between treatment and control groups and to avoid the results becoming highly dependent on the estimated models. Nevertheless, matching is no panacea, as it relies on the assumption that all the variables that account for the selection into the treatment group have been measured and included as covariates in the matching estimator. Matching therefore cannot account for any hidden (unmeasured) bias, so, in the case of positive results, additional tests are needed to instill confidence in the matching estimates (Sekhon 2009: pp. 501-503).

In particular, I use entropy balancing (Hainmueller 2012), a "matching as preprocessing" method that works as a reweighting scheme by balancing treated (VAA users) and non-treated (non-users) units on a number of covariates on the basis of their moments (mean, standard deviation, etc.). Entropy balancing has several advantages over other matching methods, as it does not discard any units from the analysis and is more flexible because weights can be used in a wide range of well-known models (e.g. logistic regression) that allow for the straightforward 
interpretation of the estimated effects. Moreover, the method has been shown to perform well in Monte Carlo simulations and to replicate the causal effects of experimental benchmarks (Hainmueller 2012).

\section{Results}

Table 1 presents estimates of the VAA mobilization effects for the four parliamentary elections conducted in Greece between 2012 and 2015. In every instance, the estimates are based on logistic regressions where the dependent variable is turnout in the previous parliamentary election and the independent variable is the self-reported usage of VAAs. The logistic regressions include inverse probability weights to match users to non-users on certain covariates based on entropy balancing (Hainmueller 2012). The covariates were chosen on the basis of being determinants of both VAA usage and turnout and include age, gender, education, political interest, and self-placement on the left-right scale.

As evident from both odd ratios and the simulated change in the individual probability of voting in the election (versus abstaining), the estimated effect is reduced with every subsequent election, becoming virtually indistinguishable from zero in 2015. Moreover, even in the case of the May 2012 election, the effect does not appear to be statistically significant. This is most likely because the 2012 Voter Survey appears to be underpowered to detect the magnitude of such an effect, since the analyses of the 2012 data include frequency weights in addition to the inverse probability weights in order to adjust the sample for the mixed mode design of the survey. In all instances, however, the analyses failed placebo tests (not shown here) when knowledge of VAAs was examined as an alternative

Table 1: VAA Mobilization Effects in Greece.

\begin{tabular}{lrrr}
\hline & \multicolumn{1}{l}{$n$} & & ATT \\
\cline { 3 - 4 } & & Odds ratio & $\Delta$ probability of voting (\%) \\
\hline May 2012 & 890 & $2.745[0.866,8.703]$ & $9.5[<0.01,19.13]$ \\
June 2012 & 896 & $2.643[0.752,9.283]$ & $6.2[<0.01,12.67]$ \\
January 2015 & 1013 & $1.098[0.414,2.915]$ & $-0.09[-3.94,4.8]$ \\
September 2015 & 806 & $1.034[0.445,2.401]$ & $-0.41[-9.14,9.9]$ \\
\hline
\end{tabular}

Average treatment effects based on a logistic regression weighted by entropy balancing for age, gender, education, political interest and left-right self-placement. The 2012 estimates include additional post-stratification survey weights. $95 \%$ confidence intervals are given in square brackets. 
“placebo" treatment (see Gemenis and Rosema 2014: p. 287). This implies that, even if the study would have had a larger sample size, the assumption that selfselection into the treatment can be controlled for on the basis of the covariates included in the analysis would not hold.

So far, most of the studies on VAA effects on turnout that performed direct comparisons between VAA users and non-users, including the evidence presented here, did not account for the hypothesized mechanisms as set out in the theory. In other words, the comparisons did not take into account the information that the VAA communicated to the users. According to the theory postulated in this paper, however, VAAs are supposed to motivate citizens to participate in elections precisely on the basis of communicating information to them about party positions. We should therefore expect that the purported effect is conditional on the quality or usefulness of the provided information. The question then is how we can measure the quality or usefulness of VAA information. Some surveys include items that specifically ask respondents to recall which party they were matched to by the VAA, and this information can be used to compare the mobilization effect between those who received matches that either confirmed or disconfirmed their initial voting intention (see e.g. Enyedi 2016). Such measurements, however, are prone to recall error due to cognitive dissonance. Moreover, this distinction does not address the fact that many VAA users do not have preferences that they want to check up on but, instead, are genuinely puzzled about who to vote for and actively seek information (see Van de Pol et al. 2014). Alternatively, studies have measured the quality of VAAs in general by asking them whether they perceived VAAs as being biased in favor of certain parties (Enyedi 2016). However, it is questionable whether such measures can be used as proxies for the usefulness of the personalized information provided by VAAs.

Analyzing VAA log files (e.g. Alvarez et al. 2014; Dinas et al. 2014; Germann and Mendez 2016; Rosema and Louwerse 2016; Garry et al. Forthcoming) makes it possible to measure the information that was communicated to VAA users. However, shifting the analysis to VAA-generated data in our case implies dropping the control group of non-users. Nonetheless, this strategy can be instrumental in reflecting on the hypothesized mechanism after establishing the presence or absence of the purported effect using survey data. For instance, Dinas et al. (2014) examined about 8000 respondents of the EU Profiler VAA across several EU member states who volunteered to participate in the opt-in questionnaire. They found a relationship between the self-assessed impact of the VAA on their vote and the "representational deficit," the degree to which the ideological profile of the respondent matches the configuration of party positions in their country.

The analysis of January 2015 Choose4Greece data (Konstantinidis et al. 2018) allows for an analogous, but different, investigation of the hypothesized 
information mechanism. As mentioned in the previous section, the design of the VAA website included a page with supplementary questions, including a question about the likelihood that the user would vote in the January 2015 parliamentary election ( 1 = "Very likely" to 4 = "Not at all likely"), before users could see the results. After users viewed the results indicating the degree of match with each of the parties contesting the election, the same question on the turnout likelihood was repeated later as a pop-up window inviting users to help the VAA designers with their research. ${ }^{3}$ Combining the responses on the pages before and after the results, allows us to generate a variable measuring the mobilization (or demobilization) of users before/after viewing the VAA matching results.

Moreover, by combining user responses with the coded party positions used in Choose4Greece (Gemenis et al. 2016), we can recreate the degree of match with each party that was communicated to each user. ${ }^{4}$ Taking the standard deviation of matches across all parties in the VAA provides a good approximation of whether Choose4Greece users were confronted with informative results or not. A high standard deviation implies that the user was given a result that included both high and low (negative) matches with parties, in other words that there were considerable differences among parties in terms of their policies. Conversely, a low standard deviation among the matches implies no differentiation among parties. An illustration of low and high standard deviation in the presented Choose $4 G$ reece matches is given in Figure 1.

Figure 2 presents the conditional effect of this information measure to the degree of mobilization, controlling for age, gender, education, political interest, and left-right self-placement, conditional on various demographic variables. As can be seen from the very large confidence intervals around the estimates, the effects are estimated with considerable uncertainty due to the small variability in the dependent variable: of the roughly 4000 respondents who answered both pre and post-result questions, approximately 95\% reported the same likelihood of voting before and after viewing the results. ${ }^{5}$ More importantly, and irrespective

3 Relying on the responses of those who answered the opt-in survey questions risks making the sample unrepresentative of VAA users at large. Despite this, there are several studies investigating VAA effects that rely exclusively on data from such opt-in surveys (e.g. Alvarez et al. 2014; Dinas et al. 2014; Garry et al. Forthcoming).

4 While Choose4Greece uses various methods to communicate information to users, the primary visualization (that also appears first) is a bar chart where parties are ordered by the degree of proximity to the user following an algorithm that is a mixture of the city-block distance and a scalar product following the directional theory of voting (see Mendez 2012).

5 The original number of respondents was further reduced after dropping suspect entries (see Mendez et al. 2014). 

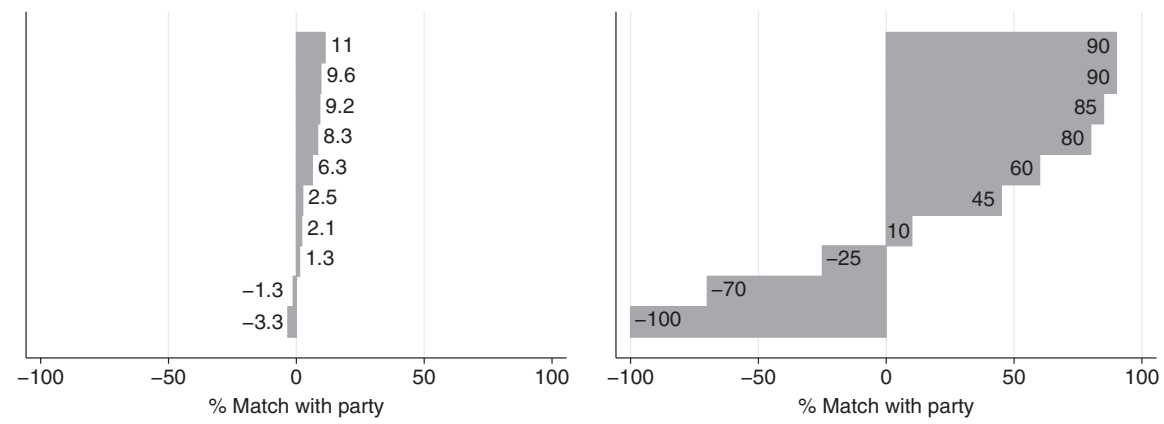

Figure 1: Choose4Greece voting advice results with low (left) and high (right) information value.
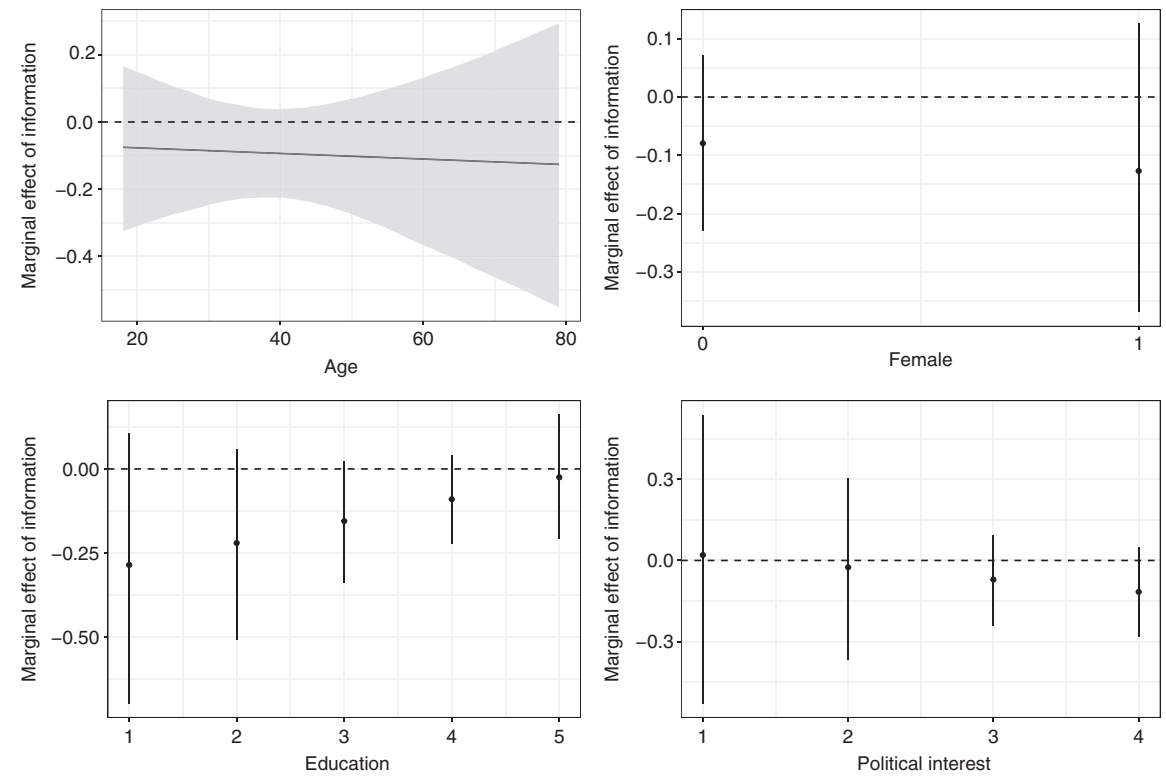

Figure 2: Estimating the conditional effect of the information provided by Choose4Greece on mobilization.

of some minor differences across the values of the conditioning variables, the marginal effects of information on mobilization are negative, implying that more differentiation among parties leads to demobilization. While this generally goes against theoretical expectations about the relationship between ideological polarization and electoral turnout, the findings are consistent with prior empirical findings which showed that the demobilizing effects of policy divergence 
among political parties are higher for those with lower education attainment (Rogowski 2014).

There are several possible explanations for these results, and these explanations relate to how the usefulness of the VAA results was measured. First, larger standard deviations among the VAA matches imply more consistency in the user response to the VAA questions. As ideological consistency is often taken as a measure of political sophistication, and sophisticated users are also less likely to change their responses pre and post-survey, this particular operationalization of VAA information could be biasing the estimates of the VAA information effects downwards. Second, larger standard deviations among the matches imply an increased likelihood of observing a party with a high match, but such ideological congruence has been shown to have an impact only on proportional electoral systems (Lefkofridi et al. 2013). Third, while larger standard deviations among the matches imply greater polarization, it has been shown that the positive effect of polarization on turnout is conditional on actual polarization at the party system level rather than perceptions at the individual level (Moral 2017).

\section{Conclusions}

The available evidence from Greece generally indicates that the effect of VAAs on turnout is marginal to non-existent, while there seems to be no evidence for the hypothesized mechanism of the purported effect. While these results may be due to limitations associated with the available data and the measurement of key concepts, it is theoretically plausible that the information mechanism under which VAAs purportedly have an impact on electoral turnout could be conditional on party system characteristics such as proportionality and polarization. Moreover, just like in Estonia, Hungary, Quebec, and Taiwan, where researchers identified only small or insignificant effects (Vassil 2011; Enyedi 2016; Wang 2016; Mahéo 2017), Greece might well fit in this group of countries where VAAs are relatively new innovations in the election campaigns and do not have the reputation and institutional support that VAAs enjoy in countries such as Finland, Germany, the Netherlands, or Switzerland. Even small effects can go a long way, however, as Kleinnijenhuis et al. (2017) argued in the case of municipal elections in the Netherlands, where aggregate data suggest that VAAs are partially successful in dampening the negative effect of demographic and socioeconomic conditions on turnout.

Overall, the findings point to the need to place more emphasis on the contextual characteristics of the countries in which VAAs operate. Future research can 
investigate this hypothesis by including appropriately worded items relating to VAA knowledge and usage in large-scale surveys (e.g. European Election Study, European Social Survey, European Values Survey) which can establish a baseline comparison of aggregate effects across different contexts. In turn, this will allow researchers to explore the relationship between VAA effects and contextual factors such as the institutional context and popularity of VAAs, as well as electoral volatility, party system fragmentation, electoral system disproportionality, and so on.

Nevertheless, while cross-national surveys and national election studies remain the workhorse of electoral research, research on VAA effects can also be served by surveys and designs that better represent specific groups where VAAs have most policy relevance: among women, low-income citizens, newly enfranchised citizens, or groups that are considered apathetic but easily reachable by technologies online (such as young people). Such research might be best served by data that oversamples these groups. Data generated from VAAs, just as employed in this study, might be helpful in this regard, especially if the analysis is not reliant exclusively on the responses of users who self-select into the additional opt-in surveys (e.g. Ladner and Pianzola 2010; Dinas et al. 2014), who are known to be systematically different compared to regular VAA users. To counter this, VAAs can be optimized for research purposes by the strategic placement of supplementary questions to maximize response rate, and by introducing elements that allow for conducting randomized experiments (e.g. Garry et al. Forthcoming).

Moreover, despite the artificiality of the setting, researchers interested in studying VAA effects on turnout should consider laboratory experiments as credible alternatives to field experiments. Laboratory experiments allow greater control over the experimental conditions, ensuring the proper implementation of the treatment condition, and, in addition, allow researchers to experiment with different methods and outputs in the way VAAs present information to users, thus drawing out important policy implications in terms of VAA design.

Finally, although this study did not reflect specifically on measurement issues facing studies of VAA effects, research on turnout more generally has illustrated how validated turnout measures are preferable over self-reported measures. While few countries offer the option of employing validated turnout data, future VAA studies should at least consider alternative wordings on measuring turnout that are known to be less affected by social desirability (Belli et al. 1999). Similarly, VAA-generated data offer the advantage of online surveys with selfadministration, which have been shown to be less susceptible to social desirability bias (Kreuter et al. 2008).

Considering the evidence from Greece and that of the previous studies, we can safely conclude that we have only scratched the surface and still have a limited 
understanding of the magnitude and mechanisms of the hypothesized effects of VAAs on voter turnout. Future studies could reflect on the available evidence as well as on the recommendations offered here and improve our understanding by examining the postulated mechanisms beyond simply comparing VAA users to non-users.

Acknowledgments: Parts of this work were supported by the framework of the Operational Program "Education and Life-long Learning” (Action “Aristeia II”), co-funded by the European Union (European Social Fund) and by national funds in Greece. Earlier versions were presented at the ECPR General Conference, University of Hamburg (August 22-25, 2018), and the ECPR Joint Sessions of Workshops, University of Nicosia (April 10-14, 2018). I would like to thank Garret Binding, Fernando Mendez, Martin Rosema, Dimiter Toshkov, and the anonymous reviewers of Statistics, Politics and Policy for their helpful comments. Any errors remain my responsibility. Replication files can be accessed at the Harvard Dataverse, doi: 10.7910/DVN/KOO6MP.

\section{References}

Alvarez, R. Michael, Ines Levin, Peter Mair and Alexander H. Trechsel (2014) "Party Preferences in the Digital Age: The Impact of Voting Advice Applications,” Party Politics, 20:227-236.

Andreadis, Ioannis, Theodore Chadjipadelis and Eftichia Teperoglou (2016) "Hellenic Voter Study 2012," Ann Arbor, MI: Inter-university Consortium for Political and Social Research [distributor], doi: 10.3886/E100022V6.

Austin, Peter C. (2011) "An Introduction to Propensity Score Methods for Reducing the Effects of Confounding in Observational Studies," Multivariate Behavioral Research, 46:399-424.

Belli, Robert F., Michael W. Traugott, Margaret Young and Katherine A. McGonagle (1999) "Reducing Vote Overreporting in Surveys: Social Desirability, Memory Failure, and Source Monitoring," Public Opinion Quarterly, 63(1):90-108.

Bimber, Bruce (2001) "Information and Political Engagement in America: The Search for Effects of Information Technology at the Individual Level," Political Research Quarterly, 54(1):53-67.

Cammaerts, Bart, Michael Bruter, Shakuntala Banaji, Sarah Harrison, Nick Anstead (2016) Youth Participation in Democratic Life: Stories of Hope and Disillusion. Basingstoke: Palgrave Macmillan.

Degan, Arianna (2006) “Policy Positions, Information Acquisition and Turnout," Scandinavian Journal of Economics, 108(4):669-682.

Dinas, Elias, Alexander H. Trechsel and Kristjan Vassil (2014) "A Look into the Mirror: Preferences, Representation and Electoral Participation," Electoral Studies, 36:290-297.

Downs, Anthony (1957) An Economic Theory of Democracy. New York: Harper and Brothers.

Enyedi, Zsolt (2016) "The Influence of Voting Advice Applications on Preferences, Loyalties and Turnout: An Experimental Study,” Political Studies, 64:1000-1015. 
Fivaz, Jan and Giorgio Nadig (2010) "Impact of Voting Advice Applications (VAAs) on Voter Turnout and their Potential use for Civic Education," Policy \& Internet, 2(4):167-200.

Franklin, Mark N. (1999) "Electoral Engineering and Cross-National Turnout Differences: What Role for Compulsory Voting?” British Journal of Political Science, 29(1):205-216.

Franklin, Mark, Cees van der Eijk and Erik Oppenhuis (1996) "The Institutional Context: Turnout." In: (Cees van der Eijk and Mark Franklin, eds.) Choosing Europe? The European Electorate and National Politics in the Face of Union. Ann Arbor: University of Michigan Press pp. 306-331.

Garry, John, James Tilly, Neil Matthews, Fernando Mendez and Jonathan Wheatley (Forthcoming) "Does Receiving Advice from Voter Advice Applications (VAAs) Affect Public Opinion in Deeply Divided Societies? Evidence from a Field Experiment in Northern Ireland," Party Politics.

Garzia, Diego and Stefan Marschall, eds. (2014) Matching Voters to Parties and Candidates: Voting Advice Applications in a Comparative Perspective. Colchester, England: ECPR Press.

Garzia, Diego, Andrea de Angelis and Joëlle Pianzola (2014) “The impact of Voting Advice Applications on Electoral Participation." In: (Diego Garzia and Stefan Marschall eds.) Matching Voters to Parties and Candidates. Colchester, England: ECPR Press, pp. 105-114.

Garzia, Diego, Alexander H. Trechsel and Andrea De Angelis (2017) "Voting Advice Applications and Electoral Participation: A Multi-Method Study," Political Communication, 34:424-443.

Gemenis, Kostas (2008) “The 2007 Parliamentary Election in Greece," Mediterranean Politics, 13:95-101.

Gemenis, Kostas (2013) “Estimating Parties’ Positions Through Voting Advice Applications: Some Methodological Considerations," Acta Politica, 48:268-295.

Gemenis, Kostas and Martin Rosema (2014) "Voting Advice Applications and Electoral Turnout," Electoral Studies, 36:281-289.

Gemenis, Kostas and Roula Nezi (2015) “Government-Opposition Dynamics During the Economic Crisis in Greece,” Journal of Legislative Studies, 21:14-34.

Gemenis, Kostas, Iannis Konstantinidis and Vasiliki Triga (2015) "Voting Advice Applications in Greece," Science and Society: Journal of Political and Moral Theory, 33:177-210. [In Greek]. Gemenis, Kostas, Vassiliki Triga and Iannis Konstantinidis (2016) "Party Positions for the January and September 2015 Parliamentary Elections in Greece," Data Archiving and Networked Services (DANS) [distributor], doi: 10.17026/dans-x8r-x3aj.

Germann, Micha and Fernando Mendez (2016) "Dynamic Scale Validation Reloaded: Assessing the Psychometric Properties of Latent Measures of Ideology in VAA Spatial Maps," Quality \& Quantity, 50:981-1007.

Germann, Micha and Uwe Serdült (2017) "Internet Voting and Turnout: Evidence from Switzerland," Electoral Studies, 47:1-12.

Germann, Micha and Kostas Gemenis (2018) "Getting out the Vote with Voting Advice Applications,” Political Communication. doi: 10.1080/10584609.2018.1526237.

Germann, Micha, Fernando Mendez, Jonathan Wheatley and Uwe Serdült (2014) "Spatial Maps in Voting Advice Applications: The Case for Dynamic Scale Validation,” Acta Politica, 50:214-238.

Green, Donald P. and Alan S. Gerber (2015) Get Out the Vote: How to Increase Voter Turnout. Second ed. Washington, DC: Brookings Institution Press.

Hainmueller, Jens (2012) "Entropy Balancing for Causal Effects: A Multivariate Reweighting Method to Produce Balanced Samples in Observational Studies," Political Analysis, 20:25-46.

Hirzalla, F., L. Van Zoonen and J. de Ridder (2010) "Internet use and Political Participation: Reflections on the Mobilization/Normalization Controversy," Information Polity, 27:1-15. 
Katsanidou, Alexia and Simon Otjes (2016) “How the European Debt Crisis Reshaped National Political Space: The Case of Greece,” European Union Politics, 17(2):262-284.

Kleinnijenhuis, Jan, Jasper van de Pol, Anita van Hoof and André Krouwel (2017) "VAAs as Sources of Volatility and Fragmentation: Self-Selection Effects and Genuine Effects," Journal of Elections, Public Opinion and Parties, 27(1):75-96.

Konstantinidis, Iannis, Kostas Gemenis, Vasiliki Georgiadou, Vasileios Manavopoulos, Fernando Mendez, Roula Nezi and Vasiliki Triga (2018) "Choose4Greece: Voting Advice Application data for the January and September 2015 parliamentary elections in Greece," GESIS-Leibniz Institute for the Social Sciences [distributor]. doi: 10.7802/1758.

Kreuter, Frauke, Stanley Presser and Roger Tourangeau (2008) "Social Desirability Bias in CATI, IVR, and web Surveys: The Effects of Mode and Question Sensitivity," Public Opinion Quarterly, 72(5):847-865.

Kruikemeier, Sanne, Guda van Noort, Rens Vliegenthart and Claes de Vreese (2014) “Unraveling the Effects of Active and Passive Forms of Political Internet Use: Does it Affect Citizens' Political Involvement?" New Media \& Society, 16:903-920.

Ladner, Andreas and Joëlle Pianzola (2010) "Do Voting Advice Applications have an Effect Electoral Participation and Voter Turnout? Evidence from the 2007 Swiss Federal Elections." In: (E. Tambouris, A. Macintosh and O. Glassey, eds.) Electronic Participation. Berlin: Springer, pp. 211-224.

Larcinese, Valentino (2009) “Information Acquisition, Ideology and Turnout: Theory and Evidence from Britain," Journal of Theoretical Politics, 21(2):237-276.

Lassen, David Dreyer (2005) "The Effect of Information on Voter Turnout: Evidence from a Natural Experiment," American Journal of Political Science, 49:103-118.

Lefkofridi, Zoe, Natalie Giger and Aina Gallego (2013) "Electoral Participation in Pursuit of Policy Representation: Ideological Congruence and Voter Turnout," Journal of Elections, Public Opinion and Parties, 24:291-311.

Liao, Da-chi, Boyu Chen, Michael J. Jensen and Colin W. Pritchard, eds. (2016) Political Behavior and Technology: Voting Advice Applications in East Asia. Berlin: Springer.

Lijphart, Arend (1997) “Unequal Participation: Democracy’s Unresolved Dilemma,” American Political Science Review, 91:1-14.

Mahéo, Valérie-Anne (2017) “Information Campaigns and (under) Privileged Citizens: An Experiment on the Differential Effects of a Voting Advice Application," Political Communication, 34:511-529.

Marantzidis, Nikos, Elias Dinas, lannis Konstantinidis, Kostas Gemenis, Roula Nezi, Lamprini Rori, Kostas Zafeiropoulos, Vasiliki Georgiadou, Anastasia Kafe and Giorgos Siakas (2017) "Collective Action of Indignant Citizens in Greece," GESIS-Leibniz Institute for the Social Sciences [distributor], doi: 10.7802/1594.

Marschall, Stefan (2014) "Profiling users." In: (Diego Garzia and Stefan Marschall, eds.) Matching Voters to Parties and Candidates. Colchester: ECPR Press, pp. 93-104.

Marschall, Stefan and Christian Schmidt (2008) "Preaching to the Converted or Making a Difference? Mobilizing Effects of an Internet Application at the German General Election 2005.” In: (David Farrell and Rüdiger Schmitt-Beck, eds.) Non-Party Actors in Electoral Politics. Baden-Baden: Nomos, pp. 259-278.

Marschall, Stefan and M. Schultze (2012) "Voting Advice Applications and their Effect on Voter Turnout: The Case of the German Wahl-O-Mat," International Journal of Electronic Governance, 5:349-366.

Mendez, Fernando (2012) "Matching Voters with Political Parties and Candidates: An Empirical Test of Four Algorithms," International Journal of Electronic Governance, 5:264-278. 
Mendez, Fernando (2017) “Modelling Proximity and Directional Decisional Logic: What can we Learn from Applying Statistical Learning Techniques to VAA-Generated Data?” Journal of Elections, Public Opinion and Parties, 27:31-55.

Mendez, Fernando, Kostas Gemenis and Constantinos Djouvas (2014) "Methodological Challenges in the Analysis of Voting Advice Application generated data." In 9th International Workshop on Semantic and Social Media Adaptation and Personalization (SMAP). IEEE Corfu, Greece, pp. 142-148. doi: 10.1109/SMAP.2014.32.

Moral, Mert (2017) "The Bipolar Voter: On the Effects of Actual and Perceived Party Polarization on voter Turnout in European Multiparty Democracies," Political Behavior, 39(4):935-965.

Nezi, Roula and Alexia Katsanidou (2014) "From Valence to Position: Economic Voting in Extraordinary Conditions,” Acta Politica, 49:413-430.

Rogowski, Jon C. (2014) “Electoral Choice, Ideological Conflict, and Political Participation," American Journal of Political Science, 58(2):479-494.

Rosema, Martin and Tom Louwerse (2016) "Response Scales in Voting Advice Applications: Do Different Designs Produce Different Outcomes?” Policy \& Internet, 8(4):431-456.

Sekhon, Sasjeet S. (2009) "Opiates for the Matches: Matching Methods for Causal Inference," Annual Review of Political Science, 12:487-508.

Smets, Kaat and Carolien van Ham (2013) "The Embarrassment of Riches? A Meta-Analysis of Individual-Level Research on Voter Turnout,” Electoral Studies, 32:344-359.

Tolbert, Caroline J. and Ramona S. McNeal (2003) "Unraveling the Effects of the Internet on Political Participation?” Political Research Quarterly, 56(2):175-185.

Tsatsanis, Emmanouil (2019) "The Swift Unreavelling: Party System Change and De-Institutionalization in Greece During the Crisis." In: (Marco Lisi, ed.) Party System Change, the European Crisis, and the State of Democracy. London: Routledge, pp. 115-136.

Van de Pol, Jasper, Bregje Holleman, Naomi Kamoen, André Krouwel and Claes De Vreese (2014) "Beyond Young, Highly Educated Males: A Typology of VAA Users," Journal of Information Technology \& Politics, 11(4):397-411.

Vassil, Kristjan (2011) Voting Smarter? The Impact of Voting Advice Applications on Political Behavior. PhD thesis European University Institute.

Walgrave, Stefaan, Peter van Aelst and Michiel Nuytemans (2008) “'Do the Vote Test': The Electoral Effects of a Popular Vote Advice Application At the 2004 Belgian Elections," Acta Politica, 43:50-70.

Walgrave, Stefaan, Michiel Nuytemans and Koen Pepermans (2009) "Voting Advice Applications and the Effect of Statement Selection," West European Politics, 32:1161-1180.

Wang, Austin (2016) “The Connection and Effectiveness of iVoter in Taiwan's 2012 Legislative Election." In: (Da-chi Liao, Boyu Chen and Michael J. Jensen, eds.) Political Behavior and Technology: Voting Advice Applications in East Asia. Basingstoke: Palgrave Macmillan, pp. 137-155.

Xenos, Michael and Patricia Moy (2007) "Direct and Differential Effects of the Internet on Political and Civic Engagement," Journal of Communication, 57(4):704-718. 